\title{
Application of a Multifunctional Additive in Cosmetic Preparations for Safe Preservation
}

\author{
ANCA MARIA J UNCAN ${ }^{1 *}$, LUCA LIVIU RUS ${ }^{1}$, VERONICA ISABELA CRACIUN ${ }^{1,2}$, ANDREEA LOREDANA VONICA TINCU1, \\ CLAUDIU MORGOVAN ${ }^{1}$ \\ ${ }^{1}$ Lucian Blaga University, Faculty of Medicine, Preclinical Department, 2A Lucian Blaga Str., 550169, Sibiu, Romania. \\ ${ }^{2}$ Polisano Pharmaceuticals SA, 156 Alba Iulia Str., 550052, Sibiu, Romania
}

The aim of this study is represented by the description and the selection of an alternative preservative complex, it's application in the development and formulation of a moisturizer and the comparative study of the efficacy of the cosmetic formulation, versus a traditional preserved cosmetic cream. For an adecvate preservation of the moisturizing cream there was used comparatively, the alternative preservation system Dermosoft LP (Caprylyl Glycol, Glycerin, Glyceryl Caprylic, Phenylpropanol), and the traditional preservative Salinip (Phenoxyethanol, Methyl Paraben, Propyl Paraben, Ethyl Paraben, Butyl Paraben, Isobutyl Paraben). Dermosoft LP has comparable effects to traditional preservatives, and proven efficacy by microbiological Challenge test.

Keywords: alternative preservation, cosmetic formulation, traditional preservatives, parabens

In recent years, there is a considerable interest in the development of preservative-free or self-preserving cosmetics [1]. Cosmetics are commercially available products, that are used to improve the appearance of the skin [2-5]. Ingredients for the preservation of personal care products require high standards of safety and compatibility. Just few of the numerous well-known and permitted preservatives are used in the majority of products. Among the more widely used materials are the parabens, which have been used successfully in cosmetic preservation for many years. Today, however, parabens are being regarded increasingly critically, both by specialists and by consumer $[6,7]$.

Alternative preservation is becoming more and more popular and many products that claim to be preservative free or paraben free are on the market. Many cosmetic manufacturers proactively use the absence of traditional preservatives to position their products. The basic core of this conflict is that, on one hand, there are good reasons to do without traditional preservatives because of toxicological matter. On the other hand there is a need for preservation in nearly all cosmetic products. The fact that an increasing number of products is nowadays preserved with alternative ingredients shows that the concept works effectively, since the same microbiological test methods are used for the assessment of products safety $[8,9]$.

There are supporters of both, traditional preservatives and alternative systems. As the differences between both terms are not always entirely clear and furthermore there are many products on the market, in which traditional preservatives are blended with alternative antimicrobial ingredients, there is still need for clarification on the definitions of traditional, alternative and natural systems for preservation. The main reason for the discrimination is not given by scientists or by efficacy data, but by the European Cosmetics Directive and other similar laws. Whenever preservatives are collected in a positive list as in Europe (Annex VI of the Cosemtics Directive 76/768/ $E E C)$, the definition of a preservative is fixed $[8,10]$.

There are many product examples showing that innovative preservation concepts are used in very successful brands. When regarding the currently most successful segment in the industry, natural cosmetics, the range of possible ingredients for preservation is limited. For the production of natural cosmetics there are selfimposed guidelines for selection of materials that have been created in different countries (ECOCERT, BDIH, NaTrue). This was necessary due to the lack of regulations and most western countries industry organizations developed guidelines to make sure that natural cosmetic products meet consumer expectations [8].

There are many choices for preservation that can be considered effective and mild. A number of cationic surfactants (like benzalkonium chloride or polyaminopropyl biguanide, clorohenesin), aromatic alcohols (phenoxyethanol, benzyl alcohol) and organic acids (sorbic acid, dehydroacetic acid, benzoic acid and others) already present an effective tool for preservation. However, there are more antimicrobials that are legally not classified as preservatives, but have been used for many years in thousands of cosmetic products. The concept behind the multifunctional ingredients was approximately 30 years ago and nowadays established in the cosmetic industry. The idea is to use cosmetic ingredients that have a multipurpose use, such as surfactants, wetting agents, $\mathrm{pH}$ regulators or masking agents $[8,10,11]$.

The budget of a cosmetic product does not always allow for the application of multifunctional additives. So the question is: what preservatives from Annex $V$ are safe and can be used with a clear conscience? A closer look at the science, legislation and public perception of some of the regularly used raw materials can result in figure 1 [12].

Due to the limited introduction of new preservatives, the trend for raw material manufacturers is to develop a blend that offers broad spectrum preservation with an element of natural [13].

In order to keep under control highly resistant pathogens an arm race started between the production of new toxic chemical structures against bacteria and bacterial constant adaptation to chemicals. Nowadays, more and more new chemical structures have been developed [14]. Biologically active antifungal compounds from plant origins are assumed to be more acceptable than synthetic compounds and represent a good source for antifungal agents [15]. 


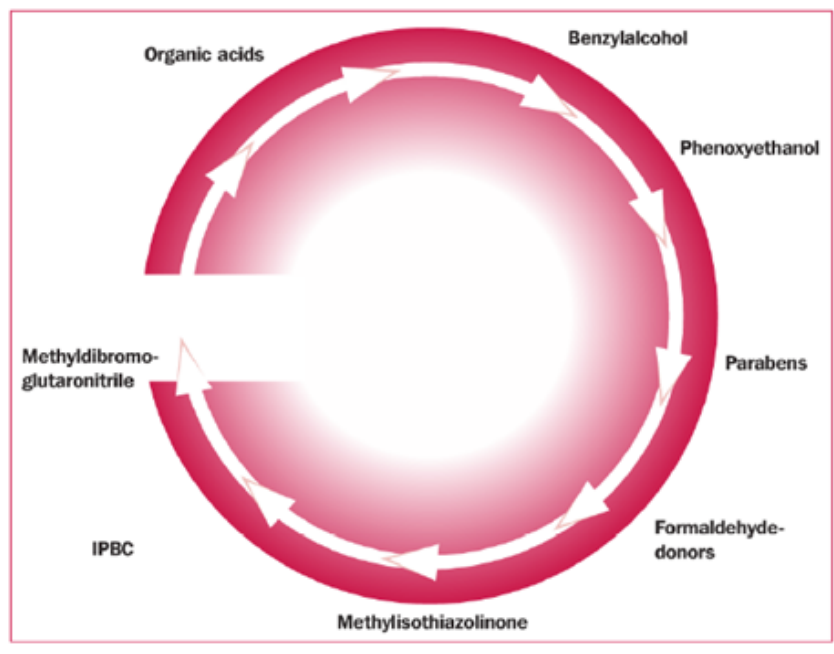

Fig. 1. Future perspectives of selected preservatives systems

Antioxidant preservatives are able to inhibit reactions promoted by oxygen, thus avoiding the oxidation and rancidity of commonly used fats, oils, waxes, surfactants, perfumes, etc. In cosmetics they are usually reducing agents and free radical scavangers [16-20].

Preservatives ensure product safety and quality and therefore play an important role in every personal care formulation. The introduction of innovative alternatives to less consumer-accepted ingredients is expanding the available toolbox of preservation options for safer and more sustainable personal care products [21].

The palette of useable preservatives has steadily declined in recent years necessitating the use of new systems to accommodate consumer preferences. No matter what system is used the priority will always be the same: to create safe and effective personal care products $[22,23]$.

The aim of this study is represented by the the selection and application of an alternative preservative complex in the development and formulation of a moisturizer and the comparative study of the efficacy of the cosmetic formulation, versus a traditional preserved cosmetic cream.

\section{Experimental part}

Materials and methods

Moisturizing Cream Formulation

For the preservation of the moisturizing cream, the multifunctional additive Dermosoft LP (Caprylyl Glycol, Glycerin, Glyceryl Caprylate, Phenylpropanol) and the traditional preservative Salinip (Phenoxyethanol, Methyl Paraben, Propyl Paraben, Ethyl Paraben, Butyl Paraben, Isobutyl Paraben) were used, comparatively.

Quantitative formulation, both traditionally preserved and preserved with multifunctional additives, on the basis of which the moisturizing cream was generically called Moisturizing Cream is presented in figure 2.

Dermosoft LP (Caprylyl Glycol, Glycerin, Glyceryl Caprylate, Phenylpropanol) is commercially available, in liquid, transparent form and is recommended for the use in cosmetic emulsions in the concentration range of 0.5$1.5 \%$ (table 1). The alternative preservative Dermosoft LP is used successfully in cosmetic formulations, because of it's low dosage recommandation, it is $\mathrm{pH}$ independent, possessing a very good broad spectrum of performance, and is especially effective against Pseudomonas (table 2).

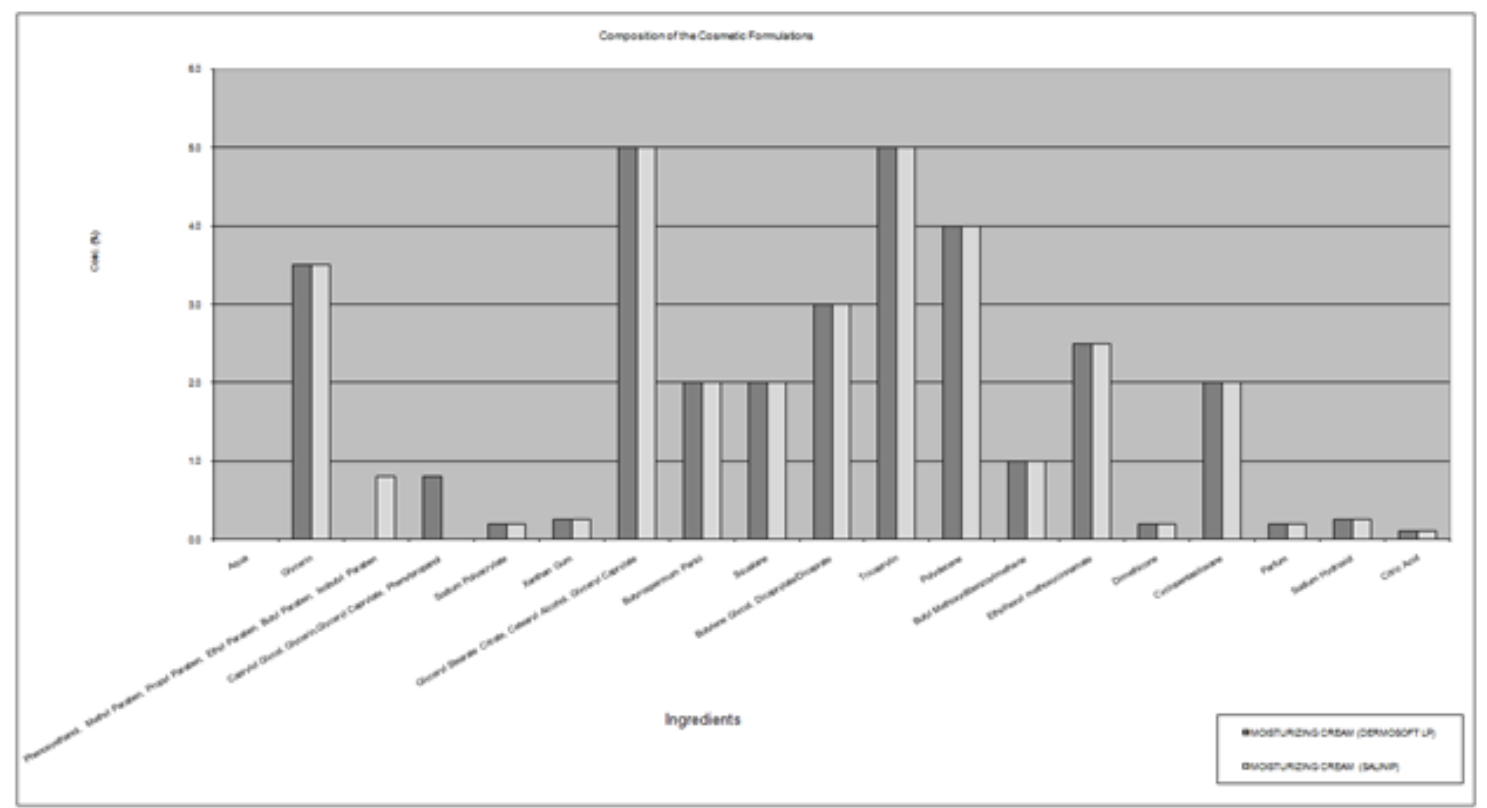

Fig. 2. Composition of the Cosmetic Formulations - Moisturizing Cream containg the alternative conservation system, vs. the tradional preservative

\begin{tabular}{|l|l|}
\hline \multicolumn{2}{|l|}{$\begin{array}{l}\text { Characteristics } \\
\text { of Dermosoft }\end{array}{ }^{\boldsymbol{T}}$ LP } \\
\hline Appearance & Clear, colourless liquid \\
\hline Odour & Mild \\
\hline INCI & Caprylyl Glycol, Glyceryl Caprylate, Glycerin, Phenyl Propanol, Aqua \\
\hline $\begin{array}{l}\text { Recommended } \\
\text { Concentration }\end{array}$ & $0.5-1.5 \%$ \\
\hline Application & $\begin{array}{l}\text { Emulsions and rinse-off products, especially phospholipid containing } \\
\text { formula }\end{array}$ \\
\hline
\end{tabular}

Table 1

CHARACTERISTICS OF THE ALTERNATIVE CONSERVATION SYSTEM DERMOSOFT LP (CAPRYLYL GLYCOL, GLYCERIN, GLYCERYL CAPRYLATE, PHENYLPROPANOL) 
Table 2

BROAD SPECTRUM PERFORMANCE OF THE ALTERNATIVE CONSERVATION SYSTEM DERMOSOFT LP (CAPRYLYL GLYCOL, GLYCERIN, GLYCERYL CAPRYLATE, PHENYLPROPANOL)

\begin{tabular}{|l|l|l|l|l|}
\hline Product & INCI- Registration & \multicolumn{2}{|c|}{ Recommended } & Performance against \\
\hline Dermosoft LP & Caprylyl Glycol; & Dosage [\%] & pH range & gram+ gram- yeast mold \\
\cline { 3 - 5 } & $\begin{array}{l}\text { Glycerin; } \\
\text { Glyceryl Caprylate; }\end{array}$ & $0.5-1.5$ & $5-7$ & $\bullet \bullet$ \\
Phenylpropanol & & & & \\
& & & & \\
\hline
\end{tabular}

The cosmetic ingredients, including preservative systems were provided from various suppliers which includes Dr. Straetmans GmbH (Germany), Ashland Specialty Chemical (UK), CP Kelco (Germany), Clariant (Switzerland), Cognis (Germany), Symrise (Germany), Dow Corning (USA), CPL Aromas (UK), Elton Corporation S.A (Romania).

\section{Manufacturing procedure}

Phase A (aqueous Phase) was heated up to $78^{\circ} \mathrm{C}$ and Sodium Polyacrylate and xanthan gum was dispersed. Phase $B$ was heated up to $78^{\circ} \mathrm{C}$. Phase $B$ was emulsyfied into Phase A under stirring and homogenized for 1-2 min., using an ultra turrax. Medium stirring was performed for cooling down. Phase C (parfum) and Phase D were added below $40^{\circ} \mathrm{C}$ and cooling down was performed under stirring.

Physico-chemical characteristics of the developed cosmetic formulation preserved with the multifunctional additive, versus the traditional preservative - Relevant Characteristics, Acceptance Criteria and Test Methods

Quality control consisted of the following determinations:

The appearance, color and odor were tested organoleptically.

$\mathrm{pH}$ determination was performed using a $\mathrm{pH}$ meter (Mettler Toledo (Schwerzenbach, Switzerland)).

Viscosity was performed using a HAAKE Viscotester VT550 (spindle $R=6$, shear rate $D=5 \mathrm{~s}^{-1}$, temperature $\left.\mathrm{T}=20^{\circ} \mathrm{C}\right)$.

\section{Accelerated stability studies}

The developed cosmetic formulation was monitored under accelerated stability studies. Accelerated stability tests were performed over a period of 30 days while maintaining the product at 4,20 and $40^{\circ} \mathrm{C}$.

\section{Antimicrobial effectiveness testing}

The test was performed according to the European Pharmacopoeia 2011:5.1.3 and according the Test for antimicrobial effectiveness (corresponding to DAB 10:VIII.14)

It was ensured that the sample is germfree. The sample was inoculated with the mentioned inocula according to the above mentioned test method. Total viable counts were carried out 2 days, 7 days, 14 days, and 28 days after inoculation. The following microbial strains were used throughout the study [24]:

- Staphylococcus aureus ATCC 6538

-Pseudomonas aeruginosa ATCC9027

- Escherichia coli ATCC 8379

- Canada albicans ATCC 10231

- Aspergillus niger ATCC 16404.

\section{Results and discussions}

Dermosoft LP (Caprylyl Glycol, Glycerin, Glyceryl Caprylate, Phenylpropanol) consits of a synergic blend of ingredients. Glyceryl caprylate is produced using only plant materials. Glyceryl monoesters have long ago been recognized as versatile antimicrobially active additives. Glyceryl caprylate has, due to its structure, moisturizing and refatting properties. This will help to improve and maintain the moisture and balanced environment of the skin. Caprylyl glycol has been a standard ingredient before with its wetting and refatting properrties and an excellent profile of antimicrobial activity. Phenylpropanol covers with its delicate scent undesired raw materials odours and boosts the fungicidal activity of the blend. Thus, the

Table 3

PHYSICO-CHEMICAL CHARACTERISTICS OF THE DEVELOPED MOISTURIZING CREAM CONTAINING THE ALTERNATIVE CONSERVATION SYSTEM DERMOSOFT LP AND THE TRADITIONAL PRESERVATIVE SALINIP

\begin{tabular}{|l|l|l|l|l|}
\hline \multicolumn{2}{|l|}{ Test } & \multicolumn{1}{|l|}{$\begin{array}{l}\text { Admissibility conditions } \\
\text { (initial) }\end{array}$} & $\begin{array}{l}\text { Admissibility conditions } \\
\text { (30 days) }\end{array}$ \\
\hline Appearance & $\begin{array}{l}\text { Moisturizing Cream } \\
\text { (Dermosoft LP) }\end{array}$ & $\begin{array}{l}\text { Moisturizing Cream } \\
\text { (Salinip) }\end{array}$ & $\begin{array}{l}\text { Moisturizing Cream } \\
\text { (Dermosofi LP) }\end{array}$ & $\begin{array}{l}\text { Moisturizing Cream } \\
\text { (Salinip) }\end{array}$ \\
\hline Odor & characteristic odor, parfumed & concordant \\
\hline Color & white & concordant \\
\hline pH & $5.5-6.0$ & concordant \\
\hline Viscosity & $30,000 \mathrm{mPas}$ & $5.5-6.0$ \\
\hline
\end{tabular}


Table 4

COLONY FORMING UNITS PER g AFTER INOCULATION

\begin{tabular}{|l|l|l|l|l|l|}
\hline \multicolumn{7}{|c|}{ Colony forming units per g after inoculation with: } \\
\hline Incubation time & $\begin{array}{c}\text { Staphylococcus } \\
\text { aureus }\end{array}$ & $\begin{array}{c}\text { Pseudomonas } \\
\text { aeruginosa }\end{array}$ & Escherichia coli & Candida albicans & Aspergillus niger \\
\hline 2 days & $<10$ & $<10$ & $<10$ & 4000 & 13000 \\
\hline 7 says & $<10$ & $<10$ & $<10$ & $<10$ & 15000 \\
\hline 14 days & $<10$ & $<10$ & $<10$ & $<10$ & 3000 \\
\hline 28 days & $<10$ & $<10$ & $<10$ & $<10$ & $<10$ \\
\hline
\end{tabular}

$0,8 \%$ Salinip

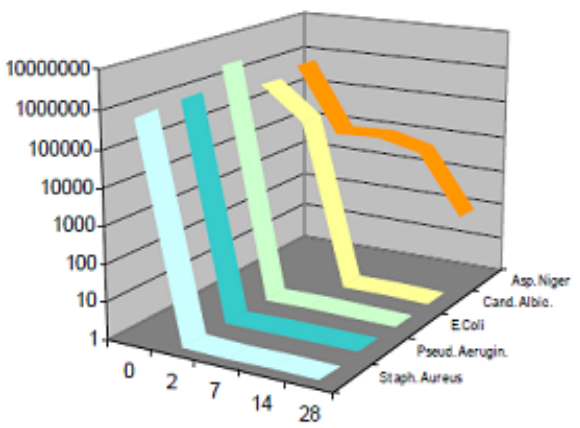

antimicrobial activity of the multifunctional additive can convert most cosmetic formulations in self-preserving products, with no need for traditional preservatives.

Quality control of the developed cosmetic cream revealed: achieving an acceptable cosmetic preparation with elegant appearance and appropriate physicochemical and pharmacotechnical (pH, viscosity) characteristics. The determination results initial, and after 30 days are shown in table 3.

Accelerated stability studies performed over a period of 30 days, while maintaining the product at 4,20 and $40^{\circ} \mathrm{C}$, showed that the formulated and studied cosmetic product is stable.

The formulations were evaluated for their efficacy to preserve the product by PCT (Preservative Challenge Test). The sample was germfree before inoculation.

Table 4 expresses the colony counting forming units per gafter inoculation for the developed moisturizing cosmetic product incorporating the multifunctional additive Dermosoft LP (Caprylyl Glycol, Glycerin, Glyceryl Caprylate, Phenylpropanol).

Dermosoft LP has comparable effects to traditional preservatives, proven by microbiological testing and Challenge tests by the raw material supplier. Figure 3. showes by comparison the efficay of Dermosoft LP (Caprylyl Glycol, Glycerin, Glyceryl Caprylate, Phenylpropanol) and Salinip (Phenoxyethanol (and) Methylparaben (and) Ethylparaben (and) Propylparaben (and) Butylparaben (and) Isobutylparaben) incorporated in the developed moisturizing cream.

\section{Conclusions}

We cannot draw a simple line to distinguish between traditional and alternative preservative. These can be similar in structure and for correct use there should be sufficient knowledge about the legal background, sourcing of materials and of course about their efficacy. It is also important to underline that these terms do not anything to do with good or bad preservatives. However there is a strong market trend towards preservative-free cosmetic
0,8 \% Dermosoft LP

Fig. 3. Comparison of Dermosoft LP with Phenoxyethanol/Paraben products and towards modern concepts of self-preserving formulations and the use of alternative preservative systems.

In conclusion, the described study shows that it is possible to develop 'self-preserving' cosmetic skin care products withoutcompromising on product aesthetics and product sensorial. These products can withstand multiple microbial challenges. They exhibit similar efficacy as that of products made with preservatives.

Acknowledgement: Special thanks are extended to Dr. Straetmans $\mathrm{GmbH}$ (Germany) for providing the multifunctional additive used for the development and formulation of the moisturizing cosmetic product and performing PCT for the developed cosmetic formulations.

\section{References}

1.PAPAGEORGIOU, S., VARVARESOU, A., TSIRIVAS, E., DEMETZOS, C., J. Cosmet. Sci., 61, 2010, p. 107.

2.JUNCAN, A. M., RUS, L. L., Mat. Plast.., 55, no. 3, 2018, p. 426.

3.JUNCAN, A. M., Mat. Plast., 55, no. 4, 2018, p. 644.

4.MORGOVAN, C., GHIBU, S., JUNCAN, A. M., RUS, L. L., BUTUCÃ, A., VONICA, L., MUNTEAN, A., MOā , L., GLIGOR, F., OLAH, N. K., Farmacia, 67, 3, 2019, p. 537.

5. MUNTEAN, A. C., JUNCAN, A. M., MOISA, D. G., VONICA, A. L., RUS, L. L., MORGOVAN, C., GLIGOR, F. G. BUTUCA, A., STANILA, A., Mat. Plast., 56, no. 2, 2019, p. 360.

6.WEBER, K., Cosm.Toil., 120, 1, 2005, p. 57.

7.STEINBERG, D., Cosm. Toil., 117, 4, 2001, p. 41.

8.IBARRA, F., Personal Care Magazine, 7, 2008, p. 86.

9.IBARRA, F., JANICHEN, J., Personal Care Magazine, 7, 2013, p. 53. 10.VARVARESOU, A., PAPAGEORGIOU, S., TSIRIVAS, E., PROTOPAPA, E., KINTZIOU, H., KEFALA, V., DEMETZOS, C., J. Cosmet. Sci., 31, 2009, p. 163.

11.SZYMCZAK-FRYE, L., Personal Care Magazine, 7, 2014, p. 42.

12.THIEMANN, A., JANICHEN, J., Personal Care Magazine, 9, 2014, p. 36.

13.TEAGUE, J., GUTKOWSKI, G., Personal Care Magazine, 9, 2014, p. 50.

14.LAZAR, M. N., GHEORGHE, S., ANGHELACHE, A., BANCIU, A., STOICA, C., LUCACIU, I., Rev. Chim. (Bucharest), 67, no. 8, 2016, p. 1454. 
15.RUS, C. F., ALEXA, E., SUMALAN, R. M., GALUSCA, A., DUMITRACHE, A., IMBREA, I. M., SARAC, I., PAG, A., POP, G., Rev. Chim. (Bucharest), 67, no. 11, 2016, p. 2287.

16.SALVADOR, A., CHISVERT, A., Analysis of Cosmetic Products, $1^{\text {st }}$ Ed., Elsevier, Amsterdam, 2007, p. 217-218.

17.JUNCAN, A. M., FETEA, F., SOCACIU, C., ENVIRON. ENG. MANAG. J., 13,1, 2014, p. 105.

18.JUNCAN, A. M., HODISAN, T., Rev. Chim. (Bucharest), 62, no. 4 , 2011, p. 415.
19.JUNCAN, A. M., HORGA, E. C., HODISAN, T., Studia UBB Chemia, 56, 2, 2011, p. 195-204.

20.J UNCAN, A. M., RUS, L. L., GLIGOR, F. G., MORGOVAN, C, Rev. Chim.(Bucharest), 70, no. 2, 2019, p. 555.

21.GAUCZINSKI, J., VIELKANOWITZ, C., LASBISTES, N., Personal Care Magazine, 2, 2018, p. 31.

22.SCOTT, R., Personal Care Magazine, 11, 2015, p. 20.

23.SCOTT, R., Personal Care Magazine, 9, 2017, p. 36.

24.POPESCU, C., POPESCU, C., POPESCU, B., DAAS, D., MORGOVAN, C., OLAH, N. K., Farmacia, 62, 4, 2014, p. 743.

Manuscript received: 21.06 .2018 